\title{
Factors Affecting Energy-Related Carbon Emissions in Beijing-Tianjin-Hebei Region
}

\author{
Jing-min Wang, Yu-fang Shi, Xue Zhao, and Xue-ting Zhang \\ Department of Economics Management, North China Electric Power University, No. 689 Huadian Road, Baoding 071003, China \\ Correspondence should be addressed to Yu-fang Shi; syf_92@163.com
}

Received 23 December 2016; Revised 18 April 2017; Accepted 10 May 2017; Published 6 July 2017

Academic Editor: Aimé Lay-Ekuakille

Copyright ( 2017 Jing-min Wang et al. This is an open access article distributed under the Creative Commons Attribution License, which permits unrestricted use, distribution, and reproduction in any medium, provided the original work is properly cited.

\begin{abstract}
Beijing-Tianjin-Hebei is a typical developed region in China. The development of economy has brought lots of carbon emissions. To explore an effective way to reduce carbon emissions, we applied the Logarithmic Mean Divisia Index (LMDI) model to find drivers behind carbon emission from 2003 to 2013. Results showed that, in Beijing, Tianjin, and Hebei, economic output was main contributor to carbon emissions. Then we utilized the decoupling model to comprehensively analyze the relationship between economic output and carbon emission. Based on the two-level model, results indicated the following: (1) Industry sector accounted for almost $80 \%$ of energy consumption in whole region. The reduced proportion of industrial GDP will directly reduce the carbon emissions. (2) The carbon factor for $\mathrm{CO}_{2}$ /energy in whole region was higher than that of Beijing and Tianjin but lower than that of Hebei. The impact of energy structure on carbon emission depends largely on the proportion of coal in industry. (3) The energy intensity in whole region decreased from 0.79 in 2003 to 0.40 in 2013 (unit: tons of standard coal/ten thousand yuan), which was lower than national average. (4) The cumulative effects of industrial structure, energy structure, and energy intensity were negative, positive, and negative, respectively.
\end{abstract}

\section{Introduction}

With global warming increasing rapidly, the issue of the adverse impact of the greenhouse gas with which each country is confronted is serious. China is the largest developing country in the world with rapid economic development accompanying the augmentation of energy consumption and carbon emissions. With the increase in international pressure, China actively responds to climate change issues and determines to develop low-carbon economy. As one of the members of the United Nations Framework Convention on Climate Change (UNFCCC), China possesses an ambitious goal to reduce carbon intensity by $60-65 \%$ by 2030 , from the level of 2005 in the Intended Nationally Determined Contribution (INDC) in 2015.

The Beijing-Tianjin-Hebei region, part of the large Bohai Bay economic zone, is the most developed economic zone and the largest industrial cluster in North China. Following the success of the Yangtze River Delta (YRD) and the Pearl River Delta (PRD), Beijing-Tianjin-Hebei is the third megaregion of China [1]. The integration of BeijingTianjin-Hebei region has become a major national strategy, defining its function of the area as world-class city group with the core of capital. The gradual expansion of economic scale in Beijing-Tianjin-Hebei region gives impetus to the augmentation of energy consumption and carbon emissions [2,3], which directly lead to low economic benefits, environmental pollution, and other problems [4]. The industrial transition is imperative and the optimization of energy structure is urgent. It requires regional coordinated development [5]. In addition, there are few studies about energy-related carbon emissions in Beijing-Tianjin-Hebei region, which affects the degree of research on integrated development.

Currently, there are two most widely used methods to decompose carbon emission factors, namely, structural decomposition analysis (SDA) and index decomposition analysis (IDA) [6-8]. SDA is used to analyze the influencing factors by using the input-output tables in specific years. Compared to the SDA method, the application of 
IDA model is more extensive, which mainly contains the Laspeyres index and the Divisia index. The Laspeyres index approach is easier to understand without the "zero-value" problem, but the decomposition results have large residual terms [9]. Within the Divisia index, the Logarithmic Mean Divisia Index (LMDI) is extensively applied in factor decomposition of energy-related carbon emissions because it has the perfect decomposition and has no unexplained residuals [10, 11], which was first proposed by Ang and Zhang [12]. The LMDI method has been used in different countries for researching carbon emission, such as France [13], Latin American [14], Ireland [15], Portugal [16], United States [17], European Union [18], Spain [19], South Korea [20], and China [21-28]. Based on the index decomposition methods, the main conclusion is that economic growth was regarded as the largest factor affecting the carbon emissions in China $[29,30]$. Song et al. applied the model of LMDI to decompose carbon emissions of Shandong Province into five factors, including energy structure, energy intensity, industry structure, economic output intensity, and energy consumption structure and found that per capita GDP was the largest driver in increasing carbon emissions [31, 32]. To calculate the energy carbon emissions in the Yangtze River Delta region between 1995 and 2010, Song et al. used the LMDI method to analyze the effect of economic scale, population size, energy intensity, and energy structure on carbon emissions [33]. Gao et al. analyzed the influence factors of carbon emissions in Inner Mongolia from 2001 to 2010 by using the LMDI model and revealed that the coaldominated energy structure and the fast-growing economy were the main reasons that influenced the carbon emissions [34]. The LMDI technique was used for the carbon increment of Beijing, and results showed that economic activity was the most important factor of carbon emissions growth [35, 36]. Chen and Lin used LMDI and Kaya extension methods to analyze the factors of carbon emissions in Tianjin during the period of 2005-2011 and concluded that economic output played a positive role in the increase of carbon emissions, while economic structure, energy intensity of the production sectors, and energy mix of the production sectors played negative roles [37].

In terms of the research content, the study mentioned the main influence factors on carbon emissions. Figure 2 shows that the economic output effect makes the most contribution to the increase of carbon emissions. The annual economic output might be affected by the other factors. Thus, to explain the relationship between the carbon emissions and economic output also has significant meaning to control carbon emissions with the decoupling method. The first decoupling method was provided by Tapio [38], who presented eight logical possibilities to distinguish state of decoupling. The previous decoupling method with respect to exploring China's carbon emissions was proposed by Freitas and Kaneko [39], who defined the decoupling indicator based on the influential factors given by index decomposition method. That method was used to analyze the contribution of the factors which influence energy-related carbon emissions in Jiangsu Province over the period 1995-2009 [40]. Based on the LMDI method, Zhang and Da [9] introduced the decoupling index to analyze the decoupling relationship between carbon emissions and economic growth in China.

Thus, the decoupling model based on LMDI method is appropriate to exploring the decoupling analysis, but the underlying causes of the changes of carbon emissions are difficult to find. The decoupling model utilized in this paper was proposed by Vehmas et al. [41]. Vehmas redefined decoupling and simplified decoupling exploration. Based on the LMDI method, the decoupling index can be decomposed into several factors, which may provide deeper explanation of how the carbon emissions change.

The remainder of this paper is organized as follows. Section 2 introduces the decomposition methodology of LMDI and decoupling model as well as data sources. Section 3 presents the different features of carbon emissions, discussion on the key decomposition factors of the carbon emissions based on LMDI, and discussion based on the decoupling index model. The conclusions and policy implications are summarized in Section 4.

\section{Methodology}

2.1. Decomposition Model. The LMDI can be expressed as an extended Kaya identity, which was first proposed by Kaya [42]. The original formula decomposed carbon emission into population, GDP, and energy intensity. Following Ang [43] and $\mathrm{Wu}$ et al. [44], the carbon emissions can be formulated as follows:

$$
\begin{aligned}
C & =\sum_{i=1}^{m} \sum_{j=1}^{n} C_{i j}=\sum_{i=1}^{m} \sum_{j=1}^{n} P \times \frac{G}{P} \times \frac{G_{i}}{G} \times \frac{E_{i}}{G_{i}} \times \frac{E_{i j}}{E_{i}} \times \frac{C_{i j}}{E_{i j}} \\
& =\sum_{i=1}^{m} \sum_{j=1}^{n} p \times a \times s_{i} \times e_{i} \times n_{i j} \times r_{i j} .
\end{aligned}
$$

To research the carbon emissions effectively, the change of carbon emissions between a base year 0 and a target year $t(\Delta C)$ can be defined into a kind of united effect. According to (1), the population effect $\left(\Delta C_{p}\right)$, economic output effect $\left(\Delta C_{a}\right)$, industrial structure effect $\left(\Delta C_{s}\right)$, energy intensity effect $\left(\Delta C_{e}\right)$, energy structure effect $\left(\Delta C_{n}\right)$, and carbon emission coefficient effect $\left(\Delta C_{r}\right)$ conclude the united effect. In terms of the LMDI analysis, $\Delta C$ can be elicited with the formula as follows:

$$
\begin{aligned}
\Delta C & =C^{t}-C^{0} \\
& =\Delta C_{p}+\Delta C_{a}+\Delta C_{s}+\Delta C_{e}+\Delta C_{n}+\Delta C_{r} .
\end{aligned}
$$

Since the carbon emission coefficient of fuel type $j$ has not changed for the years, $\Delta C_{r}=0$. Then

$$
\begin{aligned}
\Delta C & =C^{t}-C^{0}=\Delta C_{p}+\Delta C_{a}+\Delta C_{s}+\Delta C_{e}+\Delta C_{n} \\
\Delta C_{p} & =\sum_{i=1}^{m} \sum_{j=1}^{n} L\left(C_{i j}^{t-1}, C_{i j}^{t}\right) \ln \left[\frac{P(t)}{P(t-1)}\right]
\end{aligned}
$$


TABLE 1: Exceptional cases in the LMDI method.

\begin{tabular}{lccccc}
\hline$C_{i j}^{t}$ & $C_{i j}^{t-1}$ & $u^{t}$ & $u^{t-1}$ & $L\left(C_{i j}^{t-1}, C_{i j}^{t}\right) \ln \left(u^{t} / u^{t-1}\right)$ & $U$ \\
\hline 0 & + & + & + & 0 & $p$ \\
+ & 0 & + & + & 0 & $p, a, s_{i}$, or $e_{i}$ \\
0 & + & 0 & + & $-C_{i j}^{t-1}$ & $n_{i j}$ \\
+ & 0 & + & 0 & $C_{i j}^{t}$ & $n_{i j}$ \\
\hline
\end{tabular}

Note. $u$ denotes any decomposition factor; $U$ denotes the representative item of $u$.

$$
\begin{aligned}
\Delta C_{a} & =\sum_{i=1}^{m} \sum_{j=1}^{n} L\left(C_{i j}^{t-1}, C_{i j}^{t}\right) \ln \left[\frac{a(t)}{a(t-1)}\right], \\
\Delta C_{s} & =\sum_{i=1}^{m} \sum_{j=1}^{n} L\left(C_{i j}^{t-1}, C_{i j}^{t}\right) \ln \left[\frac{s_{i}(t)}{s_{i}(t-1)}\right], \\
\Delta C_{e} & =\sum_{i=1}^{m} \sum_{j=1}^{n} L\left(C_{i j}^{t-1}, C_{i j}^{t}\right) \ln \left[\frac{e_{i}(t)}{e_{i}(t-1)}\right], \\
\Delta C_{n} & =\sum_{i=1}^{m} \sum_{j=1}^{n} L\left(C_{i j}^{t-1}, C_{i j}^{t}\right) \ln \left[\frac{n_{i j}(t)}{n_{i j}(t-1)}\right] .
\end{aligned}
$$

$t-1$ and $t$ represent the base year and the target year, $m=3$, and $n=20$. The logarithmic mean of two positive numbers is defined as

$$
L\left(C_{i j}^{t-1}, C_{i j}^{t}\right)= \begin{cases}\frac{\left(C_{i j}^{t-1}-C_{i j}^{t}\right)}{\left(\ln C_{i j}^{t-1}-\ln C_{i j}^{t}\right)}, & C_{i j}^{t-1} \neq C_{i j}^{t}, \\ C_{i j}^{t-1}, & C_{i j}^{t-1}=C_{i j}^{t} .\end{cases}
$$

In the decomposition process, there would be some conditions such as $C_{i, j}=0$ or other $u=0$ ( $u$ denotes any decomposition factor). When the zero value exists, some exceptional cases exist in Table 1.

To elicit the contribution of each factor affecting carbon emissions, the equation estimating contribution degree of each influence factor was reported as follows:

$$
\begin{array}{r}
\eta_{u}=\operatorname{sgn}(\Delta C) \frac{\Delta C_{u}}{\Delta C}, \\
\operatorname{sgn}(\Delta C)= \begin{cases}+1, & \Delta C>0, \\
-1, & \Delta C<0 .\end{cases}
\end{array}
$$

$\eta_{u}$ denotes the contribution degree of the factor affecting carbon emission, $\eta_{u}>0$ represents the fact that the factor of $u$ is attributed to the carbon emission; on the contrary, $\eta_{u}<0$ suggests that the factor of $u$ restrains carbon emission. $\operatorname{sgn}(\Delta C)$ represents the change orientation of energy consumption carbon emissions. The value is positive when the carbon emission increases, and vice versa.

2.2. Decoupling Index Model Based on Empirical Data of Beijing-Tianjin-Hebei Region. The results calculated by the LMDI model in Section 2.1 were valuable to researching the influencing factors on the change of carbon emissions. We got that the economic output was the most important driving factor on the increase of carbon emissions in Beijing, Tianjin, and Hebei during 2003-2013. Then we tended to explore the deeper relationship between the carbon emissions and economic output for effective reduction of carbon emissions. Based on the empirical data of the Beijing-Tianjin-Hebei region from 2003 to 2013, this paper explored the decoupling degree between carbon emissions and economic output in three areas based on Vehmas model.

2.2.1. Decoupling Index. Measurement of decoupling can be divided into two forms including relative method and absolute method according to Vehmas et al. [41] and Tapio [38]. Vehmas calculation model is adopted to calculate decoupling index in this paper. Decoupling index is a ratio of the change rate of industrial waste gas discharge to the percentage change of GDP in a period of time:

$$
\mathrm{DI}^{t}=\frac{P^{t+1} / G^{t+1}}{P^{t} / G^{t}}-1 .
$$

$P^{t+1}, P^{t}$ represent industrial waste gas emission in year $t+1$ and year $t$, respectively; $G^{t+1}, G^{t}$ denote GDP in year $t+1$ and year $t$, respectively.

Then, $P$ could be changed into $C$ in this paper. $C$ denotes the carbon emission. In terms of the primitive result of LMDI decomposition method, economic output effect made an important contribution to the carbon emission. Compared with GDP, the per capita GDP is the more appropriate representative variable of economic growth. Thus, $G$ could be replaced with $A$, and $A$ denotes per capita GDP. The equation is as follows:

$$
\begin{aligned}
\mathrm{DI}^{t} & =\frac{C^{t+1} / A^{t+1}}{C^{t} / A^{t}}-1=\frac{C^{t+1} / A^{t+1}-C^{t} / A^{t}}{C^{t} / A^{t}} \\
& =\frac{\Delta(C / A)}{C^{t} / A^{t}} .
\end{aligned}
$$

$A=G / P$; thus $\Delta(C / G)$ and $\Delta(C / A)$ have maintain consistency of sign. The degrees of the decoupling process (Table 2) proposed by Vehmas (2007) could be applied here.

According to the framework shown in Table 2, six different degrees can be defined.

Decoupling means breaking the connection between energy-related carbon emission and economic performance, which indicates that the proportion of economic output caused by energy consumption is small. Furthermore, it can 
TABLE 2: Degrees of the linking process.

\begin{tabular}{lccc}
\hline Degree of linking & Changes in $C$ & Changes in $A$ & Changes in intensity \\
& $\Delta C$ & $\Delta A$ & $\mathrm{DI}^{t}$ \\
\hline Weak decoupling & + & + & - \\
Strong decoupling & - & + & - \\
Recessive decoupling & - & - & - \\
Weak coupling & - & - & + \\
Strong coupling & + & - & + \\
Expansive coupling & - & + \\
\hline
\end{tabular}

be divided into three states as strong decoupling state, weak decoupling, and recessive decoupling. Strong decoupling is the absolute decoupling state, and it indicates that economy development would not lead to large amounts of carbon emissions, while the carbon emission quantity decreases with the increase of the economic output. Weak decoupling is relative decoupling state, where carbon emissions grow in step with economy. Recessive decoupling state represents the situation that the economic output and carbon emission are both decreasing. Thus, recessive decoupling would be at the expense of the economic negative growth.

Coupling means keeping the connection between energyrelated carbon emission and economic performance. It indicates that the regional economic growth mainly depends on the energy consumption. Similarly, it can be divided into three states as strong coupling, weak coupling, and expansive coupling. Strong coupling is the most undesirable state where carbon emission is increasing while economic growth is decreasing.

\subsubsection{The Influence Factor Decomposition of $C / A$ Based on} LMDI Method. The index decomposition model only elicited the degree of decoupling, but the causes of decoupling degree could not be found yet. To better explore the carbon emission issue and provide more appropriate policies for the coordinated development of Beijing-Tianjin-Hebei, this paper combined the Vehmas decoupling model with the LMDI method to decompose the carbon decoupling index. Thus, the influence factors of $C / A$ could be analyzed based on (2), and the formula is as follows:

$$
\begin{aligned}
Y & =\frac{C}{A}=\sum_{i=1}^{m} \sum_{j=1}^{n} \frac{C_{i j}}{G / P}=\sum_{i=1}^{m} \sum_{j=1}^{n} \frac{C_{i j}}{G} \times P \\
& =\sum_{i=1}^{m} \sum_{j=1}^{n} \frac{C_{i j}}{E_{i j}} \times \frac{E_{i j}}{E_{i}} \times \frac{E_{i}}{G_{i}} \times \frac{G_{i}}{G} \times P \\
& =\sum_{i=1}^{m} \sum_{j=1}^{n} r_{i j} \times n_{i j} \times e_{i} \times s_{i} \times p, \\
\Delta Y & =Y^{t}-Y^{0}=\Delta Y_{r}+\Delta Y_{n}+\Delta Y_{e}+\Delta Y_{s}+\Delta Y_{p} .
\end{aligned}
$$

Similar to the decomposition of carbon emissions, $\Delta Y_{r}$ denotes carbon emission coefficient effect, $\Delta Y_{n}$ denotes energy structure effect, $\Delta Y_{e}$ denotes energy intensity effect,
$\Delta Y_{s}$ denotes industrial structure effect, and $\Delta Y_{p}$ denotes population effect. To maintain consistency of analysis approach, let $\Delta Y_{r}=0$; then

$$
\begin{aligned}
\Delta Y & =\Delta Y_{n}+\Delta Y_{e}+\Delta Y_{s}+\Delta Y_{p}, \\
\Delta Y_{p} & =\sum_{i=1}^{m} \sum_{j=1}^{n} L\left(Y_{i j}^{t-1}, Y_{i j}^{t}\right) \ln \left[\frac{P(t)}{P(t-1)}\right], \\
\Delta Y_{s} & =\sum_{i=1}^{m} \sum_{j=1}^{n} L\left(Y_{i j}^{t-1}, Y_{i j}^{t}\right) \ln \left[\frac{s_{i}(t)}{s_{i}(t-1)}\right], \\
\Delta Y_{e} & =\sum_{i=1}^{m} \sum_{j=1}^{n} L\left(Y_{i j}^{t-1}, Y_{i j}^{t}\right) \ln \left[\frac{e_{i}(t)}{e_{i}(t-1)}\right], \\
\Delta Y_{n} & =\sum_{i=1}^{m} \sum_{j=1}^{n} L\left(Y_{i j}^{t-1}, Y_{i j}^{t}\right) \ln \left[\frac{n_{i j}(t)}{n_{i j}(t-1)}\right] .
\end{aligned}
$$

$t-1$ and $t$ represent the year $t-1$ and the year $t, m=3$, and $n=20$. The logarithmic mean of two positive numbers is defined as same as (2). When the zero value exists, some exceptional cases could be elicited in terms of Table 1 .

Combining (9) with (7), $\mathrm{CI}^{t}$ could be decomposed as follows:

$$
\frac{\Delta Y_{n}+\Delta Y_{e}+\Delta Y_{s}+\Delta Y_{p}}{C^{t} / A^{t}}=\delta_{n}+\delta_{e}+\delta_{s}+\delta_{p} .
$$

According to (14), $\delta$ represents the relative contribution of energy structure, energy intensity, industrial structure, and population on the decoupling degree. The higher the absolute value of $\delta$ is, the higher the influence degree the factor contributes.

2.3. Data Sources. The regional data of GDP and population were collected from Beijing Statistical Yearbook (2015), Tianjin Statistical Yearbook (2015), and Hebei Statistical Yearbook (2015) [45-47]. The energy consumption data was collected from the primary, secondary, and tertiary industry. The primary industry consists of agriculture, forestry, animal husbandry, fishery, and water conservation. The secondary industry mainly includes industry and construction. The tertiary industry covers transport, storage, post, wholesale, retail, accommodation, catering, and others. The data of GDP used in this paper is added at base period price of 1978 . Using China Energy Statistical Yearbook for references, this 


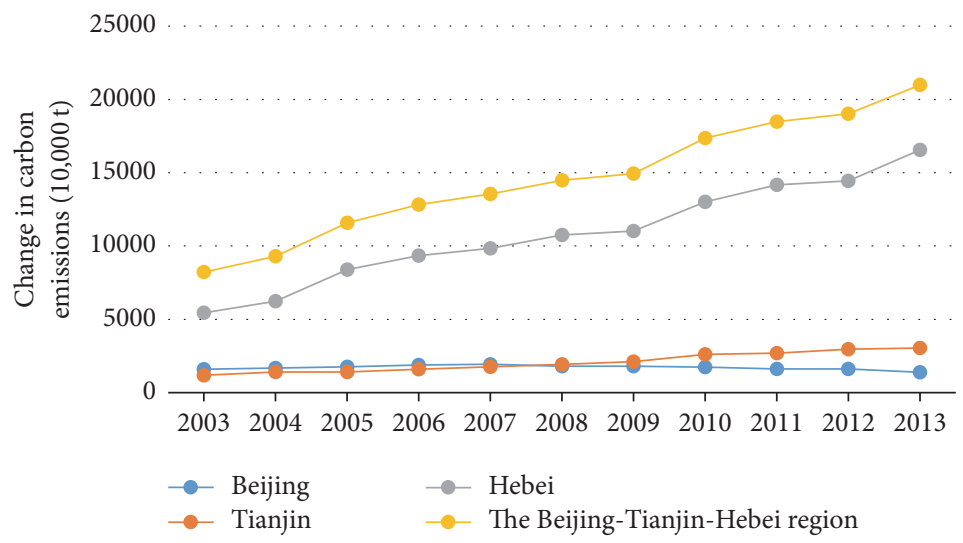

FIgURE 1: Carbon emissions in Beijing City, Tianjin City, Hebei Province, and the whole region, 2003-2013.

research employed twenty kinds of energies as follows: raw coal, cleaned coal, the other washing coal, Briquette, coke, coke oven gas, blast-furnace gas, converter gas, other coal gas, other coking products, crude oil, gasoline, kerosene, diesel oil, fuel oil, petroleum coke, liquefied petroleum gas, refinery dry gas, other oil products, and natural gas. The energy consumption data employed in this research were collected from China Energy Statistical Yearbook (2001-2014) [48]. The standard coal coefficients and the relevant carbon content value of energies are mainly quoted from GHG Protocol Tool for Energy Consumption in China (2.0) [49] and IPCC [50]. GHG Protocol Tool for Energy Consumption in China (2.0) [49] also offers some reference for the carbon coefficient estimation.

To simplify carbon coefficient estimation process, there was the hypothesis that all of the energy could convert to GHG entirely:

$$
r_{j}=c_{i} \times 10^{-6} \times \mathrm{HV}_{j} .
$$

$r_{j}$ is the carbon coefficient of the fuel type $j ; c_{i}$ is the carbon content value of the fuel type $j ; \mathrm{HV}_{j}$ is the heat value of the fuel type $j ; 10^{-6}$ is the converted coefficient from gram to ton.

This paper estimated the carbon emissions of BeijingTianjin-Hebei region with carbon emission coefficient in the basis of energy consumption, and the formula is as follows:

$$
C=\sum_{i=1}^{n} \sum_{j=1}^{m} E_{i j} \times r_{j} \times o_{j},
$$

where $C$ denotes the total carbon emissions (in $10^{4}$ ton); $E_{i j}$ denotes energy consumption of fuel type $j$ in sector $i ; r_{j}$ denotes carbon emission coefficient of fuel type $j ; o_{j}$ denotes standard coal coefficient of fuel type $j$.

\section{Results and Discussion}

3.1. Different Features of Carbon Emissions in Beijing-TianjinHebei Region. With the rapid development of the society and economy in Beijing-Tianjin-Hebei region, its energy-related carbon emissions continued to increase. Figure 1 shows the data on the carbon emissions of the Beijing-Tianjin-Hebei region, Beijing City, Tianjin City, and Hebei Province in 2003-2013.

Judging from the time scale, the overall carbon emissions in the region of Beijing-Tianjin-Hebei from 2003 to 2013 showed an increasing trend, from $8220 \times 10^{4} \mathrm{t}$ in 2003 to $20981 \times 10^{4} \mathrm{t}$ in 2013 , with a growth rate of $155.2 \%$ and an average annual growth rate of 9.8\%. During 2003-2006, 20092010, and 2012-2013, carbon emissions in Beijing-TianjinHebei region kept rapid growth with an average annual growth over $10 \%$. And it had a stable growth during the period of 2006-2009 and 2010-2012.

In terms of regional diversity, the carbon emissions from energy consumption in Hebei Province accounted for more than $66 \%$ in the whole region, which were much higher than those of Beijing City and Tianjin City. The trend of regional overall carbon emissions almost was consistent with Hebei Province. The main reason probably was that over $50 \%$ of economic growth in Hebei depends on the secondary industry, while the heavy industry mainly relies on coal as the main energy consumption, which surely leads to large amounts of energy consumption and carbon emissions. The carbon emissions in Beijing City continued to grow year after year in 2003 to 2007, 2008 to 2009, and 2011-2012 but declined during 2007-2008, 2009-2011, and 2012-2013. From 2003 to 2013, carbon emissions kept increasing in Hebei Province and Tianjin City. The energy-related carbon emissions in Hebei were much higher than Beijing and Tianjin. In 2003, the carbon emissions in Hebei Province reached $5443 \times 10^{4} \mathrm{t}$, which were 3.42 and 4.59 times that of Beijing and Tianjin, respectively. In 2013, the carbon emissions in Hebei have reached $16551 \times 10^{4} \mathrm{t}$, which were 11.93 times higher than Beijing and 5.44 times higher than Tianjin. The growth rates of energy-related carbon emissions in Hebei Province, Beijing City, and Tianjin City were $204.1 \%,-12.8 \%$, and $156.7 \%$ in 2003-2013, respectively, with average annual growth rates of $11.76 \%,-1.36 \%$, and $9.89 \%$, respectively. The highest one is Hebei Province.

3.2. Discussion on the Key Decomposition Factors of the Carbon Emissions Based on LMDI. According to LMDI model, 
TABle 3: Annual time series decomposition results and cumulative effect in Beijing-Tianjin-Hebei region from 2004 to 2013.

\begin{tabular}{lccccc}
\hline Year & Population & Economic output & Industrial structure & Energy intensity & Energy structure \\
\hline 2004 & 94.7502 & 1145.3501 & 154.8099 & -369.0096 & 73.2818 \\
2005 & 121.6941 & 1251.3962 & 195.9647 & 670.3568 & 46.6110 \\
2006 & 178.1527 & 1030.4034 & 47.4293 & -99.3840 & 513.6351 \\
2007 & 206.8274 & 1030.8941 & -108.2236 & -646.6714 & -74.4820 \\
2008 & 268.0945 & 1028.6369 & 170.0418 & -274.7525 & 119.2666 \\
2009 & 245.7581 & 960.8247 & -487.1699 & -580.5031 & 11.0862 \\
2010 & 456.3141 & 1092.6222 & 79.0454 & -302.3197 & 1161.6568 \\
2011 & 240.4441 & 1614.3404 & 205.7558 & -392.7851 & -426.1343 \\
2012 & 251.8118 & 982.1460 & -235.8155 & -308.1608 & -70.4738 \\
2013 & 247.3722 & 839.7454 & -238.3934 & -1689.5943 & 1420.1396 \\
Cumulative effect & 2311.2192 & 10976.3594 & $(-0.0158)$ & $(-0.1233)$ & 2318.7040 \\
\end{tabular}

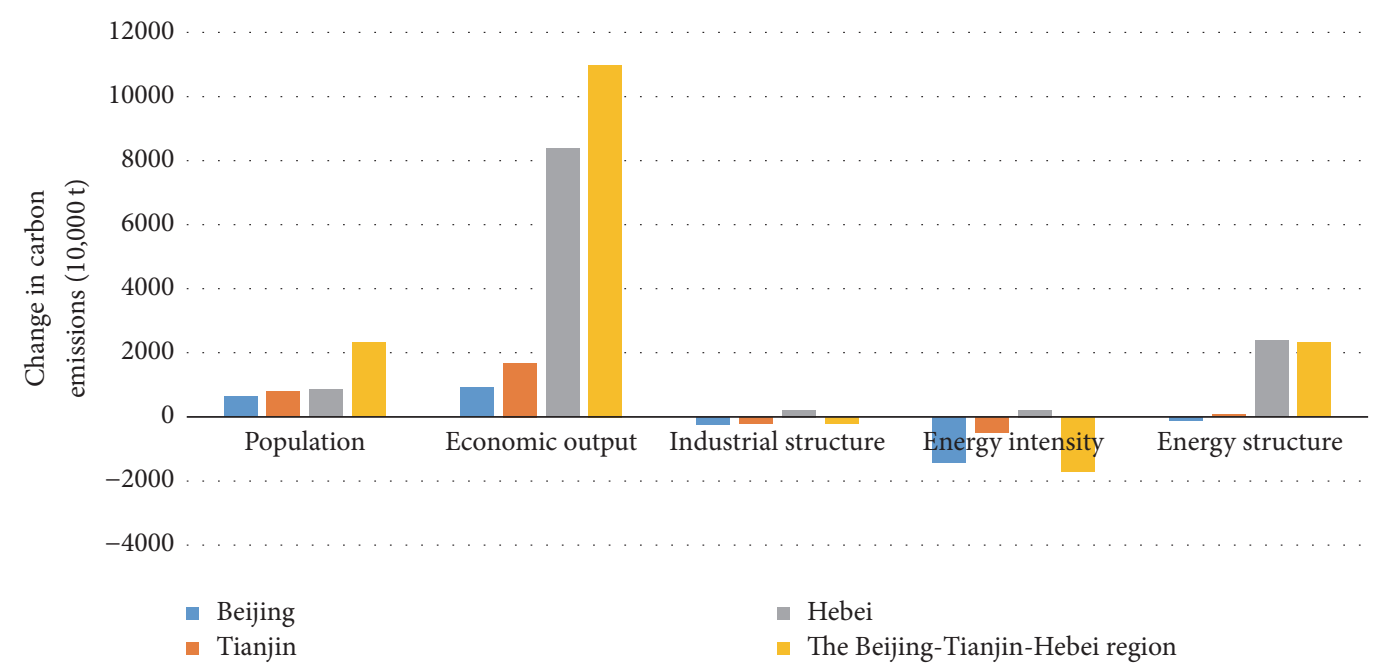

Figure 2: The cumulative effect of each decomposition factor in Beijing City, Tianjin City, Hebei Province, and the Beijing-Tianjin-Hebei region, 2004-2013.

decomposition factors affecting energy-related carbon emissions in Beijing-Tianjin-Hebei region from 2003 to 2013 were population effect, economic output effect, industrial structure effect, energy intensity effect, energy structure effect, and carbon emission coefficient effect. The annual time series decomposition results, contribution, and cumulative effects in Beijing-Tianjin-Hebei region are shown in Table 3.

From Figure 2, the cumulative effects of population and economic output are all positive in Beijing City, Tianjin City, and Hebei Province from 2003 to 2013, which exacerbates the increase of energy-related carbon emissions. The pulling effect of economic output is the largest, which means the economic output acts as the main driving factor to increase the carbon emissions in Beijing, Tianjin, and Hebei. However, the cumulative effects of industrial structure, energy structure, and energy intensity on carbon emission vary among the three regions. In Hebei Province, industrial structure and energy intensity are positive factors in increasing carbon emissions, but they are contrary in Beijing City and Tianjin City. Energy structure is attributed to reducing the carbon emissions in Beijing but increases carbon emissions in Hebei and Tianjin. This paper focuses on the three factors which have different influences on Beijing, Tianjin, and Hebei. By adjusting these factors, we can explore a path for collaborative development in the whole region.

3.2.1. Discussion on the Effect of Industrial Structure. The annual effects of industrial structure in Beijing, Tianjin, Hebei, and the whole region are shown in Figure 3. The effect of industrial structure had strong fluctuation in BeijingTianjin-Hebei region. Though the cumulative effect was negative during the studied period, it was also positive in 2004, 2005, 2006, 2008, 2010, and 2011, which increased the carbon emissions. Meanwhile, it is evident that the trend of regional industrial structure's annual effect is consistent with Hebei Province. But the changes in Beijing and Tianjin are not obvious.

As we can see from Figure 4, industry sector accounts for almost $80 \%$ of energy consumption in the whole region, which may be attributed to the development of the heavy 


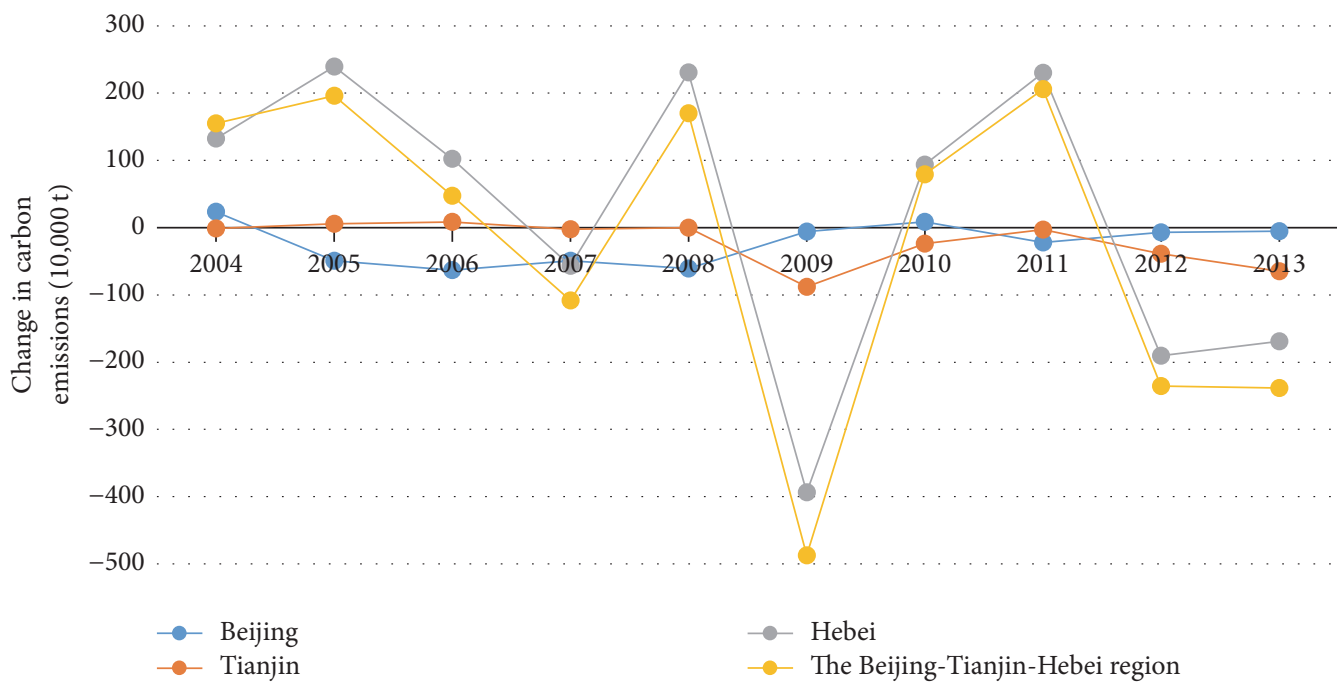

FIgure 3: The annual effect of industrial structure in Beijing City, Tianjin City, Hebei Province, and the Beijing-Tianjin-Hebei region, 2004-2013 (LMDI results).

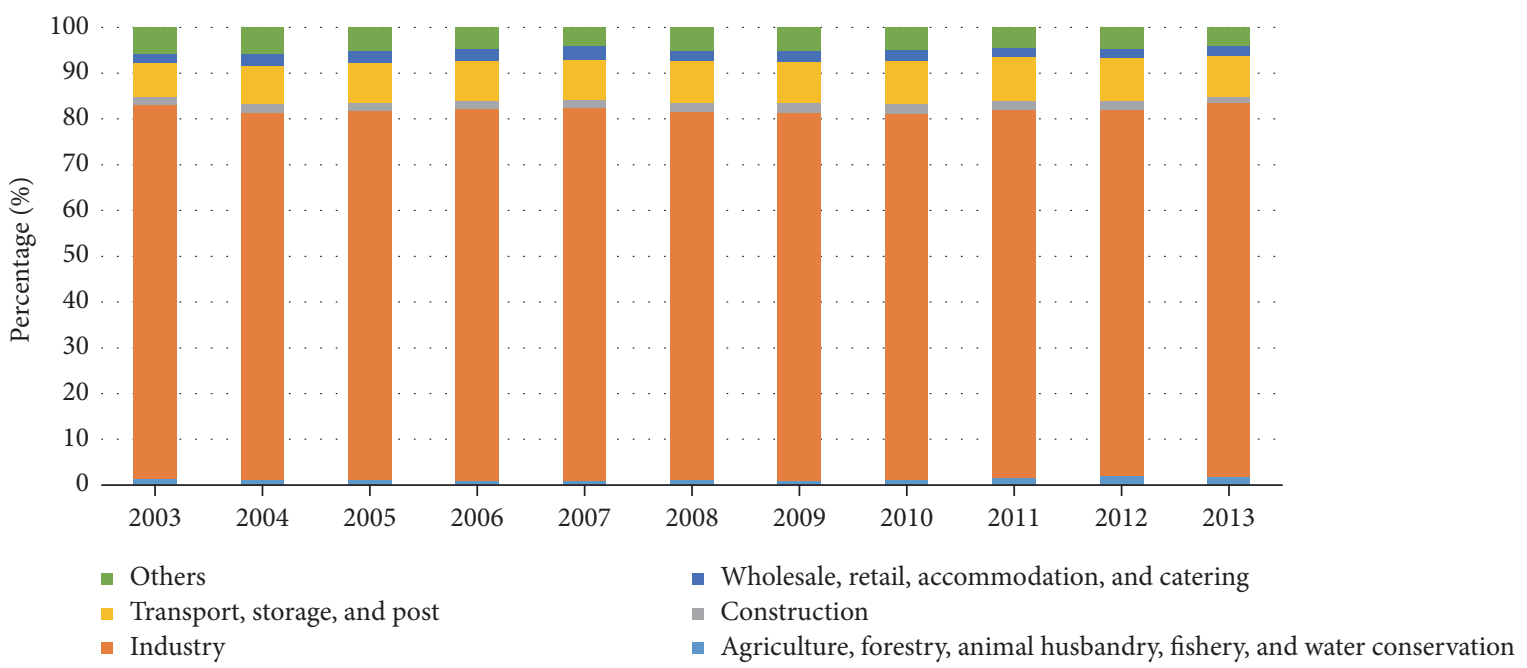

FIGURE 4: The respective proportion of energy consumption in six sectors, 2003-2013.

industrialization. Because industry sector accounts for the greatest proportion of energy consumption, we guess that a change in the proportion of GDP in industry sector will directly affect the carbon emissions, and it turns out that the industry structure influences the carbon emission.

Figure 5 reveals similar change trends for the annual effect on carbon emissions of industrial structure and the annual share of GDP in industry sector in Beijing-Tianjin-Hebei region. It indicates that the change in industrial output can affect carbon emissions. So the proportion of industry sector in regional economy should be gradually reduced for the decrease in carbon emissions. The government plays a crucial role in promoting a transition both from energy intensive industrial sectors to energy extensive industrial sectors and from low technology industries to high technology industries. And from Figure 5, we know the share of industry sector in GDP for the whole region does not change much. That may explain that the industrial structure change has minor impact on the emission reduction.

From Figures 6 and 7, the contribution of Beijing to the regional industry output decreased from $22.46 \%$ in 2003 to $15.02 \%$ in 2012, and the share in regional industry energy consumption declined from $15.91 \%$ in 2003 to $4.95 \%$ in 2012 . This demonstrates that the economic structure gives priority to the tertiary industry in Beijing, which is superior to Tianjin and Beijing. The contribution of Tianjin to the regional industry output increased from $22.34 \%$ in 2003 to $27.92 \%$ in 2012 , and the share in regional energy consumption increased from $12.19 \%$ in 2003 to $15.18 \%$ in 2012 . The proportion of the former is greater than the latter, which means there was a shift in Tianjin's economic structure toward the tertiary industry, but the secondary industry was mainly still in the dominant position. Meanwhile, the contribution of Hebei to the regional industry output increased from $55.20 \%$ in 


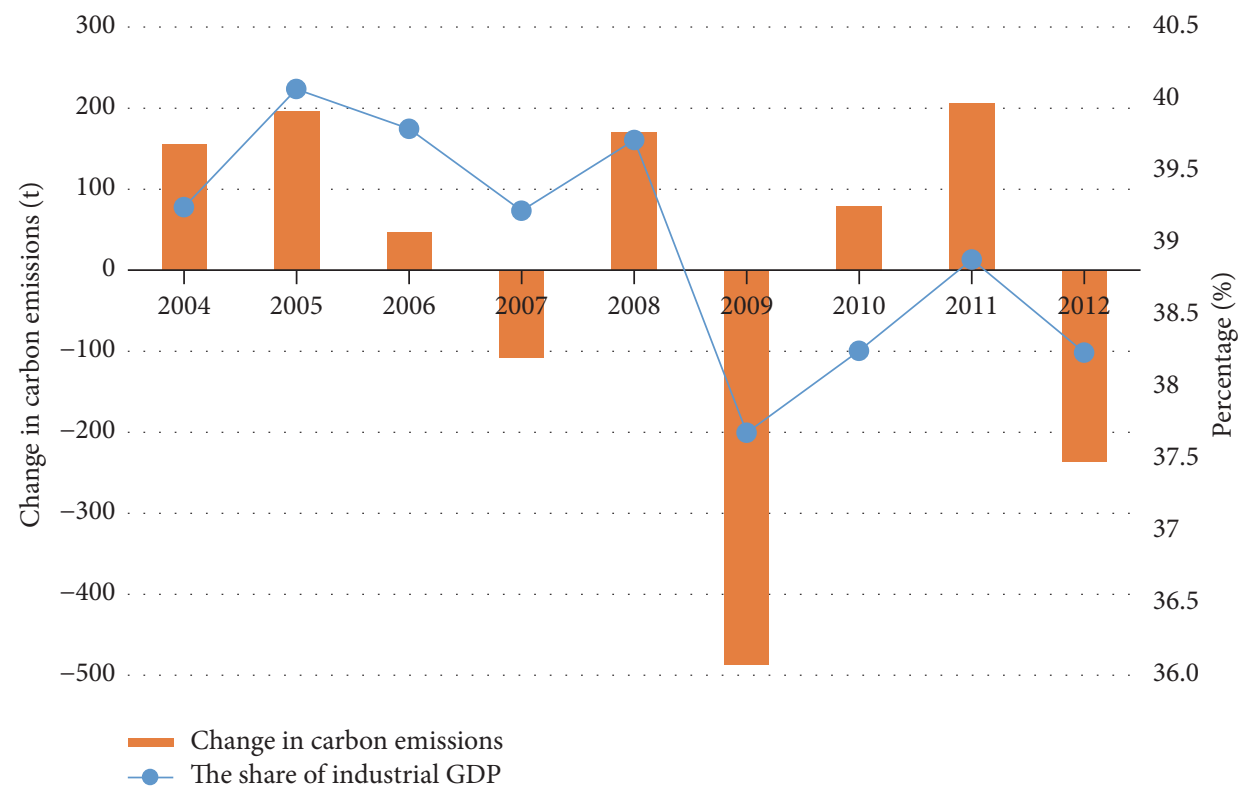

FIGURE 5: Changes in annual effect on carbon emissions of industrial structure and the share of industrial GDP in Beijing-Tianjin-Hebei region, 2004-2012.

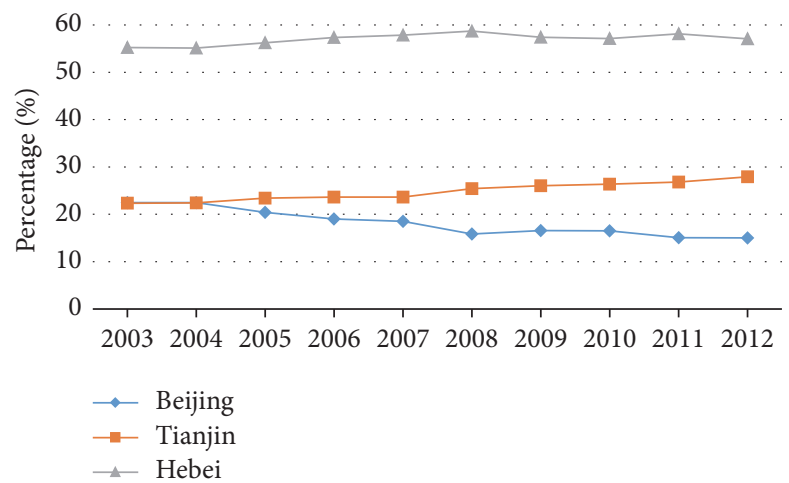

FIgURE 6: The contributions to the regional industry output of Beijing, Tianjin, and Hebei, 2003-2012.

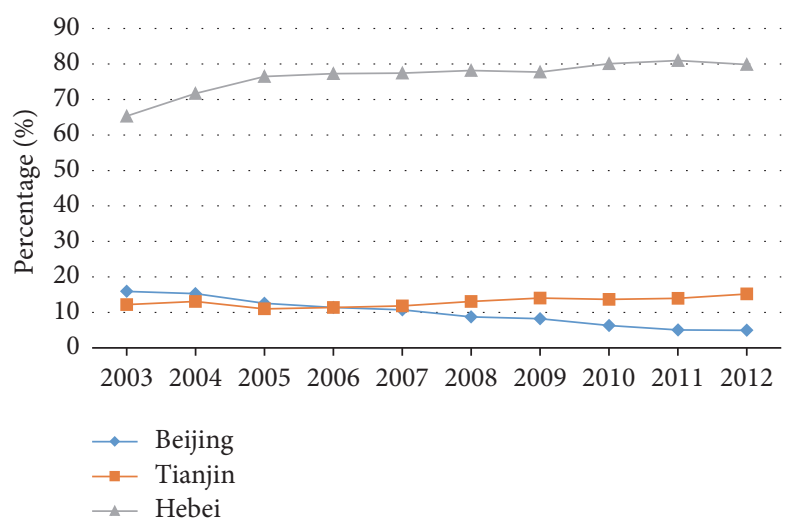

Figure 7: The contributions to the regional industry energy consumption of Beijing, Tianjin, and Hebei, 2003-2012. 


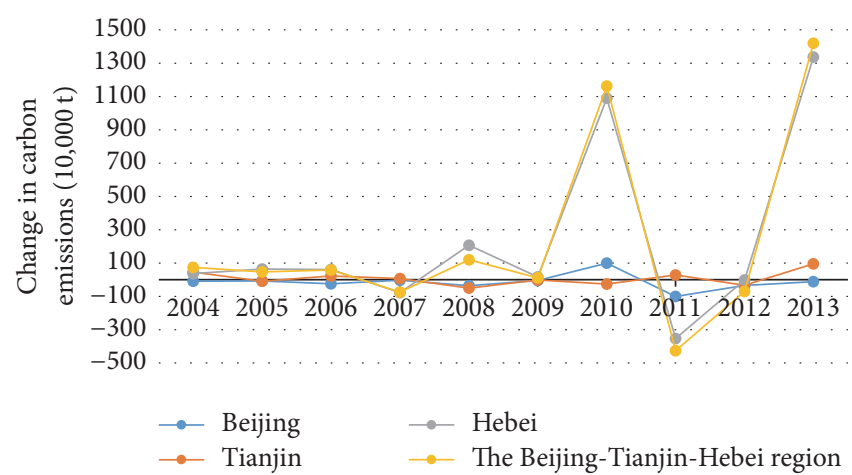

Figure 8: The annual effect of energy structure in Beijing City, Tianjin City, Hebei Province, and the Beijing-Tianjin-Hebei region, 2004-2013 (LMDI results).

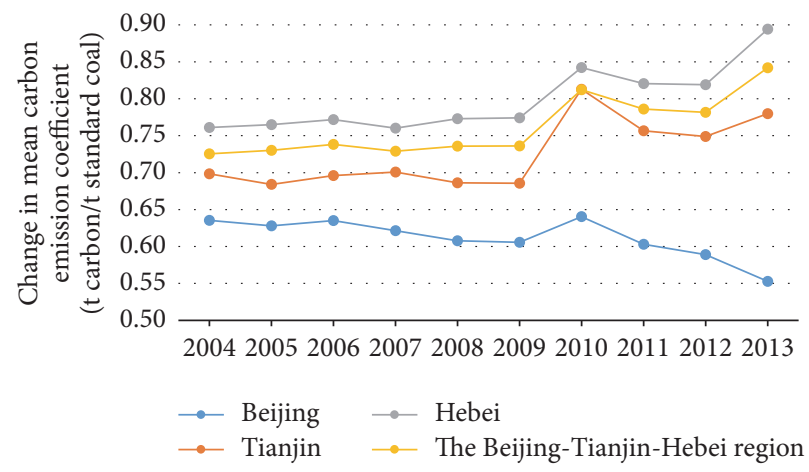

FIGURE 9: Changes in mean carbon emission coefficient in the Beijing-Tianjin-Hebei region.

2003 to $57.06 \%$ in 2012 , and the share in regional energy consumption increased from $65.31 \%$ in 2003 to $19.87 \%$ in 2012. The proportion is much higher than that in Beijing and Tianjin, which means the economic structure gives first place to the secondary industry. Furthermore, the proportion of industry output is higher than the energy consumption, representing that the economy in Hebei is mainly supported by energy intensive industries, which is unreasonable. In order to achieve the coordinated development in BeijingTianjin-Hebei region, the governments should focus on Hebei Province.

3.2.2. Discussion on the Effect of Energy Structure. Table 3 articulates the fact that, in Beijing-Tianjin-Hebei region, the energy structure plays a relatively minor role in impacting energy-related carbon emissions. From Figure 8, we can see the energy structure effect decreased the carbon emissions in three years: 2007, 2011, and 2012 and it increased carbon emissions in the rest years. The cumulative effect was positive in the period of 2003-2013. It is obvious that Hebei is the major factor in affecting the whole region. The changes in Tianjin and Beijing were not obvious. And the cumulative effects were negative in Beijing but positive in Tianjin, Hebei, and the whole region.

The average carbon emissions coefficient of energy is the ratio of total carbon emissions to total energy consumption. The carbon emission coefficient of coal is higher than other fuels, which is 1.3 times that of oil and 1.7 times that of natural gas. When the proportion of coal increases, the energy structure tends to be high-carbon, which will in turn increase both the carbon emissions and energy consumption, as well as the average carbon emissions coefficient. And the change in average carbon emission coefficient will reflect the regional energy structure and the change of carbon emissions in turn. From Figure 9, we know there are some fluctuations therein, and overall there seems to be a rising trend, which represents the fact that the region's energy structure has not been optimized. We also know that Beijing's energy structure is superior to those of the Hebei and Tianjin. The average carbon emission coefficient in Hebei is the highest, which is the main contributor in the whole region.

The energy structure effect on carbon emissions can be explained by timely changes in the region's average carbon emission coefficient. When the average carbon emission coefficient increases relative to the previous year, the energy structure has a positive effect on carbon emissions; that is, it has a pulling effect. Otherwise, it has a negative effect, which acts as a disincentive. The energy average carbon emission coefficient in the whole region shows a rising trend, reflecting the promoting effect of energy structure on carbon emissions.

In Beijing-Tianjin-Hebei region, as we all know, the industry sector accounted for about $80 \%$ of total energy consumption during 2003-2013, as shown in Figure 5. Therefore, the energy structure may be dominated by the fuel share of 


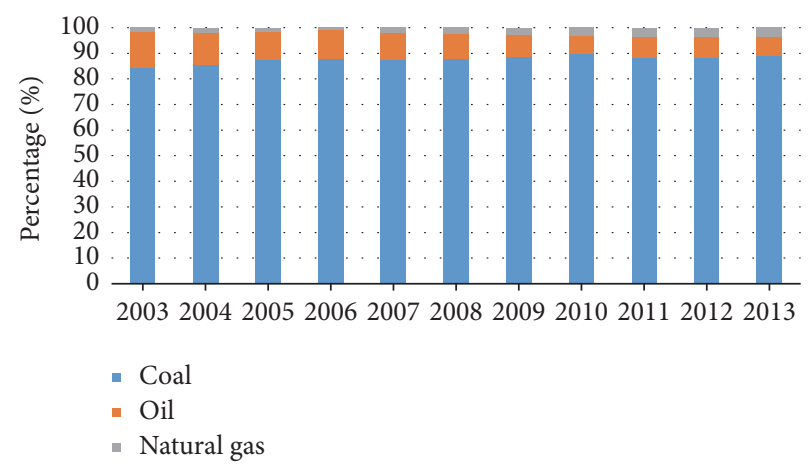

FIGURE 10: Changes in the proportion of coal, oil, and natural gas in energy consumption in industry sector in Beijing-Tianjin-Hebei region.

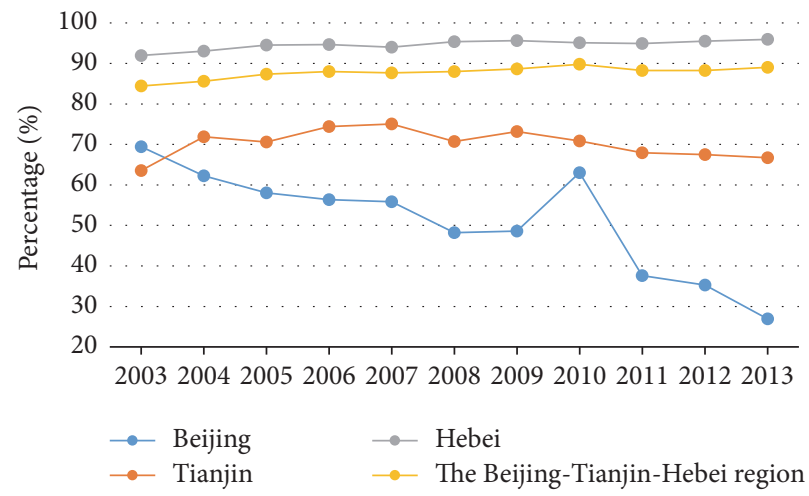

FIGURE 11: Changes in proportion of coal in industry sector in Beijing, Tianjin, Hebei, and the Beijing-Tianjin-Hebei region, respectively.

coal, oil, and natural gas in industry sector. From Figure 10, we can see the energy structure of the whole region is marked mainly by the consumption of coal, which accounts for about $84 \%-90 \%$, the same as a traditional high-carbon energy consumption form. During the studied period, the share of coal decreased just in 2007 and 2011 and increased in the other years. Comparing Figure 8 with Figures 9 and 10, the annual effect of energy structure on carbon emissions reveals similar trends, as well as the change in the average carbon emission coefficient and the annual rate of change in the proportion of coal in industry sector. It indicated that the reduction of coal can inhibit the increase of carbon emissions to some extent. The proportion of oil in terminal energy is about $6 \%-14 \%$ and the proportion of natural gas is just $1 \%-4 \%$. The proportion of coal and natural gas increased from $84.43 \%$ and $1.63 \%$ in 2003 to $89.04 \%$ and $3.60 \%$ in 2013 , respectively, and the share of oil decreased from $13.95 \%$ in 2003 to $7.36 \%$ in 2013 . The little change of the proportion of coal, oil, and natural gas may explain why the effect of energy structure is not big.

The shares of coal in Beijing, Tianjin, Hebei, and the whole region are shown in Figure 11. We can see the share of coal in Hebei represented a growth trend during 2003-2013, with its proportion increasing from $91.97 \%$ in 2003 to $95.93 \%$ in 2013. It dropped in 2007, 2010, and 2011 in Hebei Province, which stayed the same trend as the whole region. The trend of Tianjin first rose and fell, remaining at around $70 \%$. There basically seems a downward trend in the share of coal in Beijing, with its share declining from $69.45 \%$ in 2003 to
$26.92 \%$ in 2013. From the above analysis, we know Hebei Province is the main contributor to the regional high share of coal. To optimize the regional energy structure and decrease the carbon emissions, it is necessary to reduce the proportion of coal in industry sector, especially Hebei Province. In addition to that, the government should develop clean energy, such as solar energy and wind energy for the development of low-carbon economy.

3.2.3. Discussion on the Effect of Energy Intensity. Energy consumption intensity is the ratio of energy consumption to GDP. The annual effect of energy intensity in Beijing, Tianjin, Hebei, and the whole region is shown in Figure 12. Table 3 reveals that in 2005 and 2007 the energy intensity effect on carbon emissions was positive and negative in the rest years, which means it decreased the carbon emissions. The cumulative effects of energy intensity in Beijing, Tianjin, and the whole region were negative, which was the main driving factor to decrease the carbon emissions. However, the cumulative effect in Hebei was positive. The changes in carbon emissions in Beijing and Tianjin for energy intensity effect were relatively small. Hebei is the main contributor to affecting the carbon emissions in the whole region.

Figure 13 shows the change trend in energy intensity of the average level in China, the Beijing-Tianjin-Hebei region, Beijing City, Tianjin City, and Hebei Province from 2003 to 2013. China implemented quite a lot of energy efficiency policies to improve energy efficiency and energy 


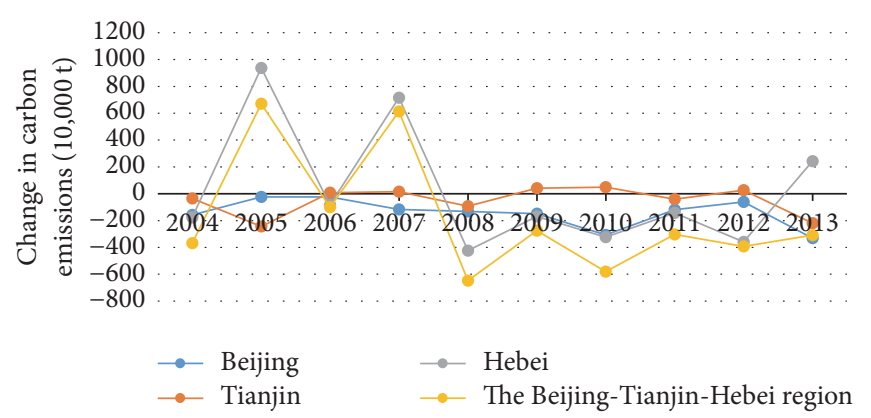

Figure 12: The annual effect of energy intensity in Beijing City, Tianjin City, Hebei Province, and the Beijing-Tianjin-Hebei region, 2004-2013 (LMDI results).

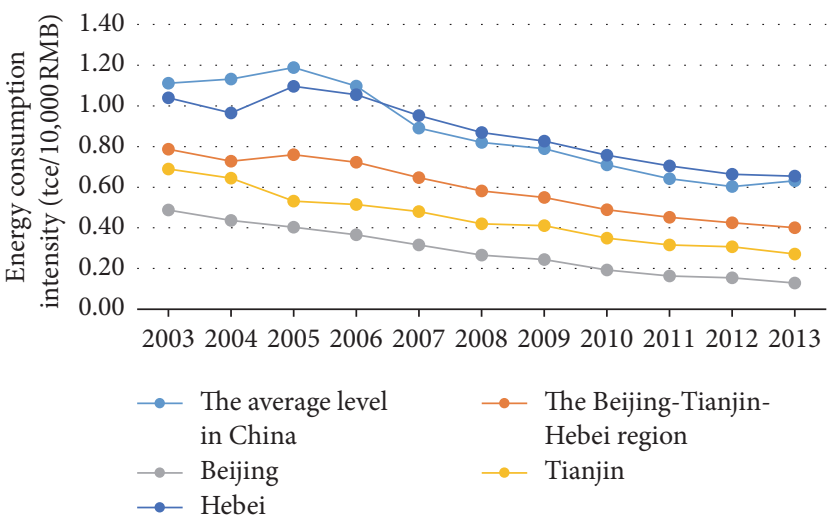

FIGURE 13: The comparison of energy consumption intensity among the average level in China, the Beijing-Tianjin-Hebei region, Beijing City, Tianjin City, and Hebei Province, 2003-2013.

consumption productivity. China's Energy Conservation Law came into force in 1998, and energy efficiency label system was established in 2003. The implementation of those policies promotes the improvement of energy efficiency. As one of the most developed regions in China, the compliance rate in Beijing-Tianjin-Hebei region is relatively high for such energy efficiency policies. It can be proved from Figure 13. The energy intensity in the whole region is lower than national average. That is to say, the energy efficiency in the developed region is higher than the national average. What is more, we can see the trend in the studied regions is downward from 2003 to 2013. Energy intensity reflects the energy efficiency and economic activity. The decrease in energy intensity implies an improvement in energy efficiency, which includes the technical efficiency and resource use efficiency, especially in industry sector. The energy efficiency in Beijing is better than Tianjin and Hebei, and the worst is Hebei. To improve the regional energy efficiency, Hebei would be the key of the governance. Even though there was a fluctuation in the energy intensity during the period, the energy intensity in Beijing-Tianjin-Hebei region decreased from $0.79 \mathrm{t}$ of standard coal/ten thousand yuan in 2003 to $0.40 \mathrm{t}$ of standard coal/ten thousand yuan in 2013, but the energy intensity in Beijing has reached $0.13 \mathrm{t}$ of standard coal/ten thousand yuan. The energy efficiency is high, which is consistent with the result of Fan and Lei [51]. There is still considerable potential for the whole region to reduce the energy intensity, particularly in industry sector with the highcarbon energy.

3.3. Discussion Based on the Decoupling Index Model. We can explore the relationship between carbon emissions and economic output in Beijing-Tianjin-Hebei region from 2003 to 2013 based on decoupling index. The results are shown in Table 4.

3.3.1. Discussion on Decoupling Index. Table 4 reveals the results of decomposition of $C / A$ decoupling in each region from 2004 to 2013. We can see that in Beijing three states of decoupling occurred in the study period: weak decoupling, recessive decoupling, and strong decoupling. Weak decoupling occurred during 2004-2009, except 2008. In 2008, it represented recessive decoupling in Beijing for hosting the Olympic Games. To guarantee the environment fit for that, Beijing limited the operation of some high-carbon emission industries. The reduction of carbon emission was in accord with economic recession. The development from 2010 to 2013 showed strong decoupling. In Tianjin, weak decoupling only occurred in three years: 2005, 2008, and 2013. The rest of the years were expansive decoupling. There is no obvious decoupling trend in Tianjin. In Hebei, expansive coupling occurred from 2004 to 2013, except for 2008-2009 and 20112012, where the decoupling state was weak decoupling. In 
TABLE 4: Results of decomposition of C/A decoupling in each region from 2004 to 2013.

\begin{tabular}{|c|c|c|c|c|c|}
\hline Region & Year & $\Delta C$ & $\Delta A$ & $\mathrm{CI}^{t}$ & The state of decoupling \\
\hline \multirow{10}{*}{ Beijing } & 2004 & 82.2549 & 907.9179 & -0.1240 & Weak decoupling \\
\hline & 2005 & 93.0453 & 794.3069 & -0.0219 & Weak decoupling \\
\hline & 2006 & 118.1122 & 831.2095 & -0.0217 & Weak decoupling \\
\hline & 2007 & 51.6837 & 868.5864 & -0.0314 & Weak decoupling \\
\hline & 2008 & -139.6115 & -114.7105 & -0.0636 & Recessive decoupling \\
\hline & 2009 & 4.7818 & 523.7645 & -0.0378 & Weak decoupling \\
\hline & 2010 & -55.6673 & 381.4855 & -0.0587 & Strong decoupling \\
\hline & 2011 & -139.1345 & 465.0947 & -0.1070 & Strong decoupling \\
\hline & 2012 & 12.7725 & 662.6193 & -0.0383 & Weak decoupling \\
\hline & 2013 & -232.0206 & 864.9265 & -0.1917 & Strong decoupling \\
\hline \multirow{10}{*}{ Tianjin } & 2004 & 215.4325 & 777.7076 & 0.0365 & Expansive coupling \\
\hline & 2005 & 18.2434 & 1402.3028 & -0.1459 & Weak decoupling \\
\hline & 2006 & 179.7578 & 1498.8953 & 0.0565 & Expansive coupling \\
\hline & 2007 & 166.6062 & 499.7505 & 0.0492 & Expansive coupling \\
\hline & 2008 & 171.0587 & 1253.3215 & -0.0249 & Weak decoupling \\
\hline & 2009 & 183.2053 & 825.6878 & 0.0200 & Expansive coupling \\
\hline & 2010 & 495.7178 & 1016.9117 & 0.1201 & Expansive coupling \\
\hline & 2011 & 87.1362 & 1146.2256 & 0.0331 & Expansive coupling \\
\hline & 2012 & 258.2167 & 964.0158 & 0.0263 & Expansive coupling \\
\hline & 2013 & 81.9576 & 786.5973 & -0.0228 & Weak decoupling \\
\hline \multirow{10}{*}{ Hebei } & 2004 & 783.1910 & 376.6417 & 0.0179 & Expansive coupling \\
\hline & 2005 & 2166.7845 & 400.9591 & 0.1930 & Expansive coupling \\
\hline & 2006 & 940.5937 & 330.6326 & 0.0158 & Expansive coupling \\
\hline & 2007 & 508.2274 & 356.2731 & 0.0652 & Expansive coupling \\
\hline & 2008 & 910.7886 & 351.7516 & -0.0003 & Weak decoupling \\
\hline & 2009 & 267.7595 & 320.1379 & -0.0428 & Weak decoupling \\
\hline & 2010 & 1989.2082 & 396.5953 & 0.0912 & Expansive coupling \\
\hline & 2011 & 1168.8598 & 547.5265 & -0.0132 & Weak decoupling \\
\hline & 2012 & 264.5138 & 300.2448 & -0.0316 & Weak decoupling \\
\hline & 2013 & 2107.6708 & 246.3678 & 0.1013 & Expansive coupling \\
\hline
\end{tabular}

2008, the decoupling index sizes of Beijing, Tianjin, and Hebei were relatively smaller than previous years, mainly because a series of energy policies were conducted for the 2008 Olympic Games, which reduced the carbon emissions in Beijing, Tianjin, and Hebei. This phenomenon suggested that the government played the crucial role in the carbon emission reduction in the developing country.

3.3.2. Decomposition Analysis of Decoupling Index. In Beijing, according to Figures 14 and 15, the decoupling sizes of energy-related carbon emissions and economic output obviously expanded from small to big. The results showed that energy intensity was the major factor to decoupling state. The cumulative effect of energy intensity was -0.8470 , and the contribution was 121.67 to the decoupling. The values of population decoupling subindex were positive during the time horizon, and the value increased from 0.024 continuously, until 2008 where the subindex of population reached the maximum which was 0.0531 and then began to decline. After 2004, the industrial structure subindexes were negative except 2010, all of which made contributions to the decoupling. The energy structure subindexes basically remained negative except 2007 and 2010. The cumulative effect of population, industrial structure, energy intensity, and energy structure were $0.3570,-0.1228,-0.8470$, and -0.0834 , respectively. These data indicated that the technical level, industrial structure, and energy structure had made contributions to the development of regional low-carbon economy.

In Tianjin, from Figures 14 and 16, the decoupling tendency was not obvious continuously, while the decoupling indexes changed periodically. The population subindexes were positive from 2004 to 2013. Energy intensity subindexes contributed to the decoupling of energy-related carbon emissions and economic output synthetically and the cumulative effect was -0.2587 . The industrial structure subindexes changed with a downward tendency, which decreased from 0.0435 in 2003 to -0.0213 in 2013 . However, the cumulative effect of industrial structure was only -0.0392 , which was less than the energy intensity. Owing to the slight decline in the proportion of coal consumption, the energy structure subindexes were positive except the years 2005, 2008, and 


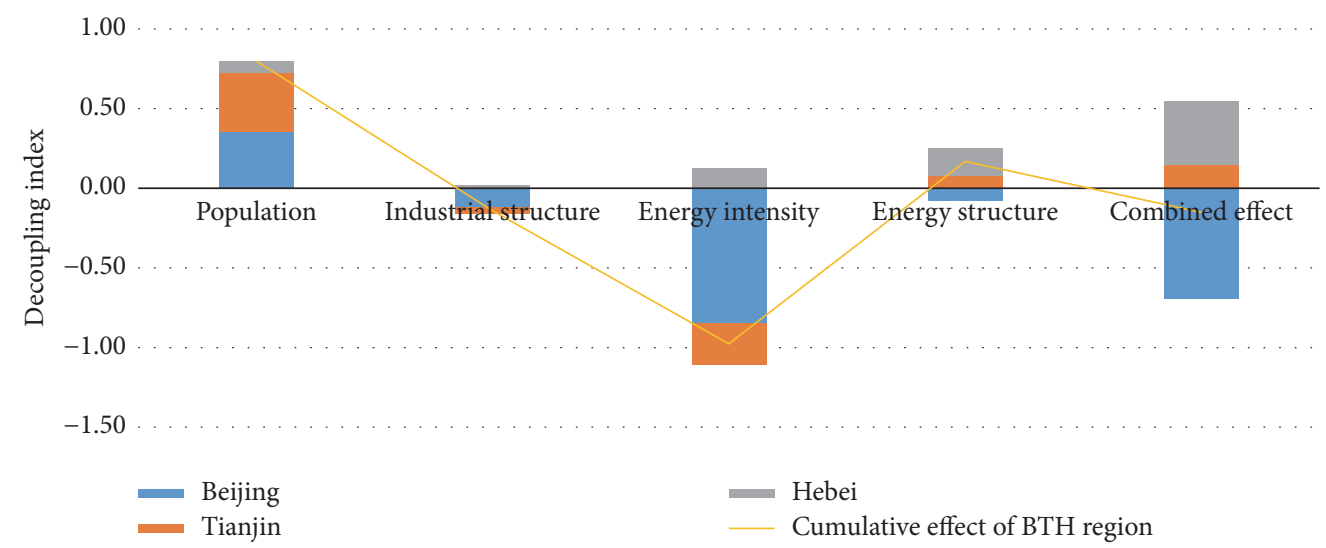

FIGURE 14: The cumulative effect value of influence factors at regional level.

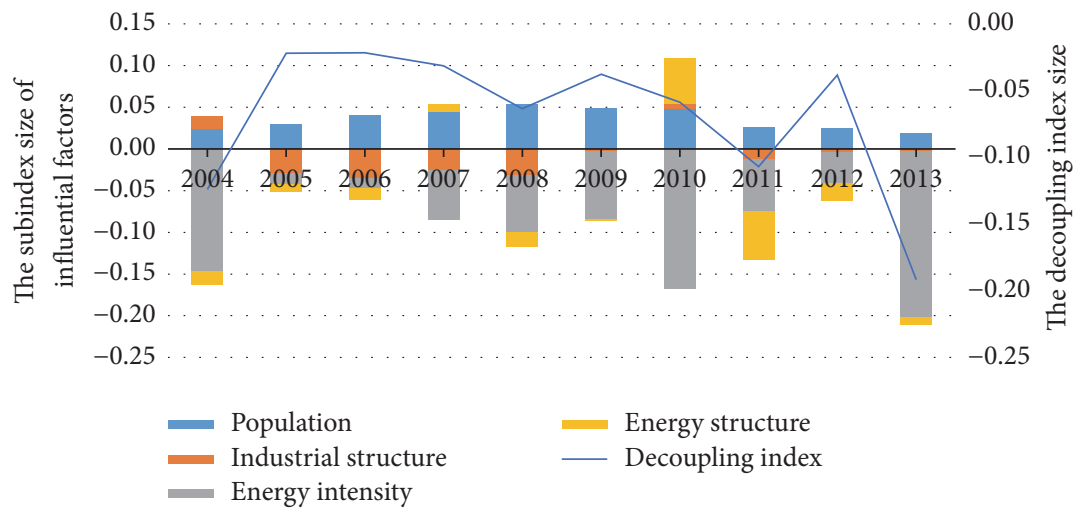

FIGURE 15: Decomposition of decoupling index over 2004-2013 in Beijing.

2012. The cumulative effect of energy structure was 0.0776 , which had negative effect on the decoupling of energy-related carbon emissions and economic output synthetically. But the energy structure gradually promoted decoupling since 2005, mainly because China green energy industry BBS was held in Tianjin in 2005, which provided a series of significant recommendations regarding chemical and physical power industry to adjust energy structure. The data showed that energy intensity effect and industrial structure effect both contributed to the decoupling of the carbon emissions and economic output, while the industrial structure played a minor role in the decoupling degree. In Tianjin, the energy intensity effect was also the most important driving factor for decoupling. Only in 2005, 2008, and 2013, did the decoupling indexes represent weak decoupling because of the prominent contribution from energy intensity effect. While the energy intensity subindex became negative or just decreased, the decoupling index would change into negative or decrease simultaneously.

Based on the data showed in Figures 14 and 17, Hebei might be confronted with the pressing situation and critical period of emission reduction. The weak decoupling state in Hebei only occurred in 2008-2009 and 2011-2012. In contrast to Beijing and Tianjin, Hebei's population effect, whose cumulative effect was 0.0738 , played a minor role in decoupling between the carbon emissions and economic output. The industrial structure subindexes were negative only in 2007, 2009, and 2012-2013, and their value reached 0.1413 in 2005 , accounting for $73.2 \%$ of the decoupling index size. The reason might be that Shougang Group, a large steel company, was transferred from Beijing to Hebei. So the industrial structure subindex in Beijing changed from 0.0151 in 2004 to -0.0287 in 2005 . The results showed that the steel enterprises with high fossil fuel consumption have large influence on the native carbon emissions and decoupling degree. The energy intensity subindexes were negative except 2005, 2007 , and 2013. However, the cumulative effect of industrial structure was 0.0279 , smaller than the cumulative effect of energy intensity, which was 0.1278. Meanwhile, the energy structure subindexes changed between 0.0015 and 0.0089 during 2004-2009, but it is not the most important factor in inhibiting the decoupling. After 2009, the size of energy structure effect became obvious. In 2013, there was an industry crisis, where industries in Hebei were confronting with the new energy enterprises, such as photovoltaic industry. Thus, the energy structure subindex was 0.0893 , which accounted for $88.75 \%$ of the decoupling index that year, since Hebei is a traditional agricultural province, with its industry development lower than the national average in other areas, making its energy structure a negative influence on decoupling. 


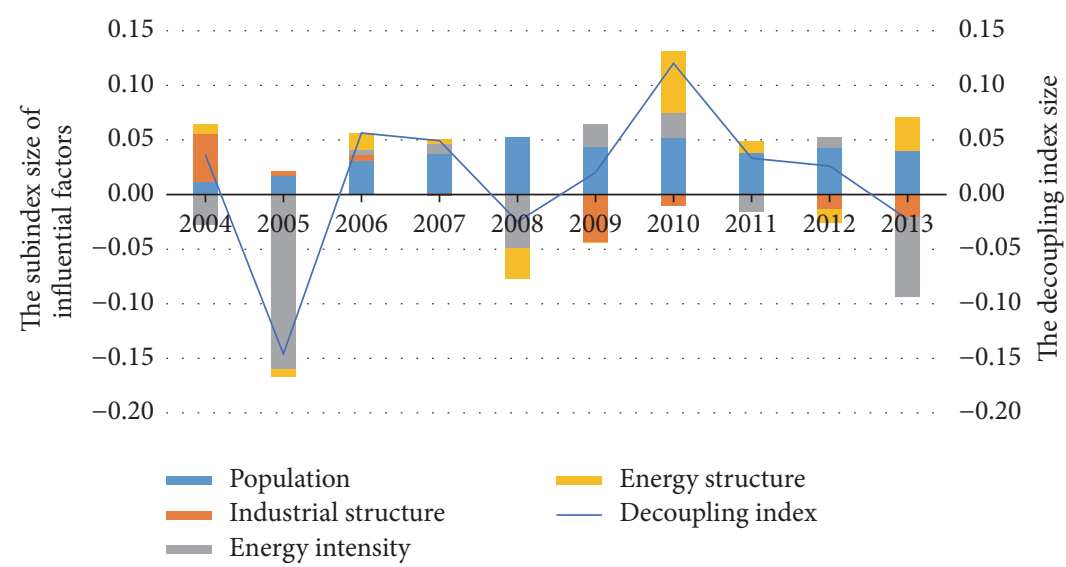

FIgURE 16: Decomposition of decoupling index over 2004-2013 in Tianjin.

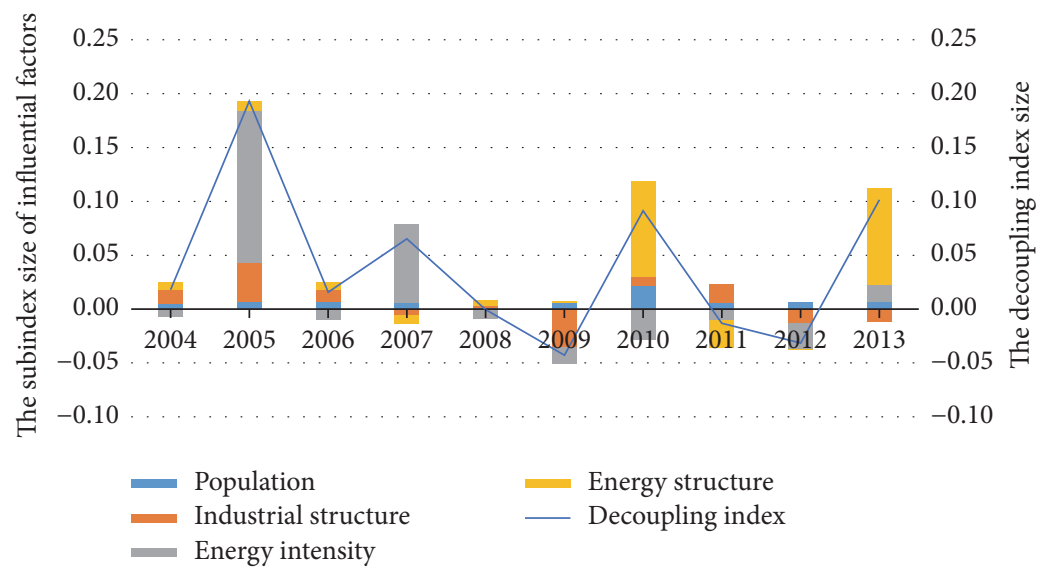

FIGURE 17: Decomposition of decoupling index over 2004-2013 in Hebei.

The different decoupling states occurred in Beijing, Tianjin, and Hebei and also were partly attributed to the different process and situation of industrialization. Beijing is in the middle-later state of industrialization, and the regional industrial structure and energy structure were relatively appropriate to the development of low-carbon economy. The industrialization degree of Tianjin is the middle periods, and the industrial structure should be further optimized; meanwhile, the energy structure should be adjusted gradually. The industrialization in Hebei started relatively late; then the regional industrialization is still in the earlier stage. The industrial structure and energy structure have not formed a certain scale, both of which need the vigorous expansion.

\section{Conclusions and Policy Implications}

Based on the LMDI method, this paper elicits the influence factor of carbon emissions. Compared with other factors, the economic activity effect has the continuously positive influence on carbon emission during 2003-2013 besides the population effect. Then, this paper further analyzes the decoupling state of carbon emissions and economic output based on Vehmas model. Conclusions are as follows:
(1) The energy-related carbon emissions in BeijingTianjin-Hebei region increased from $8220 \times 10^{4} \mathrm{t}$ in 2003 to $20981 \times 10^{4} \mathrm{t}$ in 2013 , with a growth rate of $155.2 \%$ and an average annual growth rate of $9.8 \%$.

(2) Industry sector accounts for almost $80 \%$ of energy consumption in Beijing-Tianjin-Hebei region. The analysis shows that the decrease in the proportion of GDP in industry sector will directly reduce the carbon emissions. And the cumulative effect was negative in the decoupling index.

(3) In the regional energy consumption, coal accounts for about $84 \%-90 \%$ in industry sector. And the mean carbon emission coefficient in the whole region is higher than that of Beijing and Tianjin, but lower than that of Hebei. The effect of energy structure on carbon emission was mainly affected by the proportion of coal in industry sector. And the cumulative effect was positive in the decoupling index.

(4) The energy intensity in Beijing-Tianjin-Hebei region decreased from 0.79 tons of standard coal/ten thousand yuan in 2003 to 0.40 tons of standard coal/ten thousand yuan in 2013, which is lower than the national average. And the cumulative effect was negative in the decoupling index.

According to the above analysis, we make the following recommendations. 
In terms of industrial structure, the energy consumption in industry sector is the highest. The trend of the whole region is mainly consistent with the Hebei Province. Therefore, it is necessary to promote the energy saving and emission reduction in the promise of not affecting the economic development in Hebei Province. The most effective way is industrial upgrading which is upgrading and rebuilding the high energy consumption industry, eliminating the backward production, and optimizing the excess capacity effectively. Hebei should further reenact the industry access threshold and improve the market environment to enhance the support of the tertiary industry, especially in the emerging service of energy, family, pension, information consumption, green credit industry, and so forth. We may realize the optimization and upgrade of productive enterprises relying on industrial park construction, improve the ability of independent innovation, and develop high and new technology industry.

In terms of energy structure, coal is considered as the main energy in Beijing, Tianjin, and Hebei. The energy structure is unreasonable and the cardinality of carbon emissions is large. Through the analysis on decomposition results of energy-related carbon emissions, the reduction of coal can reduce carbon emissions to some extent. Accordingly, energy conservation and carbon emissions reduction work should be focused on the reduction of coal's proportion and the optimization of energy consumption structure. By further analysis, the proportion of coal in Hebei Province is the highest in the whole region, nearly more than $85 \%$ in recent ten years. The proportion of coal in Tianjin City is the second in the whole region, more than $48 \%$. And the lowest proportion of coal consumption is only about $20 \%$ in Beijing. Therefore, it is necessary to adjust the energy structure of Hebei and Tianjin to reduce the proportion of coal in Beijing-TianjinHebei region. Combined with the relevant data, the coal in Beijing and Tianjin is mainly used for power generation and heating. Therefore, for the whole region, especially in Hebei and Tianjin, it must always adhere to the cleanness use of fossil energy and developing the policies to combine the nonfossil energy. On one hand, Hebei and Tianjin should strengthen the clean utilization of coal, improve the efficiency utilization of coal, and strengthen the processing of carbon emissions at the same time; on the other hand, the region should gradually reduce the proportion of coal and oil in energy consumption, increase the supply of natural gas and the intensity of "coal to gas," and further add the proportion of renewable energy. Moreover, it should actively build a scientific and reasonable multiple complementary energy consumption structure, which significantly cuts down the carbon emissions of energy consumption in Beijing-TianjinHebei region.

\section{Definition of Variables in (1)}

\author{
$C:$ Total carbon emissions \\ $m$ : Index of industrial sector \\ $n$ : Index of fuel type \\ $C_{i j}$ : Carbon emissions of the $i$ th sector based \\ on fuel type $j$
}

$E_{i j}$ : Consumption of $i$ th industrial sector based on fuel type $j$

$E_{i}$ : Total energy consumption of $i$ th industrial sector

$G_{i}$ : Output of $i$ th industrial sector

$G$ : Gross domestic product (GDP)

$P$ : Population

$a$ : Per capita gross domestic product (GDP)

$s_{i}$ : Share of economic output of the $i$ th sector in GDP

$e_{i}$ : Consumption per unit of output in the $i$ th industrial sector

$n_{i j}$ : Energy share from the use of energy type $j$ in $i$ th industrial sector

$r_{i j}$ : Carbon emission coefficient of fuel type $j$.

\section{Conflicts of Interest}

The authors declare that there are no conflicts of interest regarding the publication of this paper.

\section{Acknowledgments}

This research was supported by the Social Science Foundation of Beijing (no. 15JGB050).

\section{References}

[1] jing-jin-ji, 2014, http://www.china-briefing.com/news/2014/07/ 11/jing-jin-ji-biggest-city-china-youve-probably-never-heard .html.

[2] Y. Wang, Y. Wang, J. Zhou, X. Zhu, and G. Lu, "Energy consumption and economic growth in China: a multivariate causality test," Energy Policy, vol. 39, no. 7, pp. 4399-4406, 2011.

[3] X. H. Zhang, R. Zhang, L. Q. Wu, S. H. Deng, L. L. Lin, and X. Y. Yu, "The interactions among China's economic growth and its energy consumption and emissions during 1978-2007," Ecological Indicators, vol. 24, pp. 83-95, 2013.

[4] J. Lu, W. Fan, and M. Meng, "Empirical research on China's carbon productivity decomposition model based on multidimensional factors," Energies, vol. 8, no. 4, pp. 3093-3117, 2015.

[5] J. Dong, "Financial Difficulties and solutions for industrial transfer under the integration of Beijing-Tianjin-Hebei region," in Proceedings of the 5th International Conference on Education, Management, Information and Medicine (EMIM 2015), Atlantis Press, Shenyang, China, April 2015.

[6] X. Wang, Y. Qin, X. Jiang, and Y. Sun, "Study for the carbon emission influencing factors of Henan province based on LMDI model," International Conference on Geoinformatics, Article ID 6626186, 2013

[7] G. P. Peters, C. L. Weber, D. Guan, and K. Hubacek, "China’s growing $\mathrm{CO}_{2}$ emissions a race between increasing consumption and efficiency gains," Environmental Science \& Technology, vol. 41, no. 17, pp. 5939-5944, 2007.

[8] D. Guan, K. Hubacek, C. L. Weber, G. P. Peters, and D. M. Reiner, "The drivers of Chinese $\mathrm{CO}_{2}$ emissions from 1980 to 2030," Global Environmental Change, vol. 18, no. 4, pp. 626-634, 2008.

[9] Y. J. Zhang and Y. B. Da, “The decomposition of energy-related carbon emission and its decoupling with economic growth in 
China," Renewable and Sustainable Energy Reviews, vol. 41, pp. 1255-1266, 2015.

[10] Y. Zhang, J. Zhang, Z. Yang, and S. Li, "Regional differences in the factors that influence China's energy-related carbon emissions, and potential mitigation strategies," Energy Policy, vol. 39, no. 12, pp. 7712-7718, 2011.

[11] B. W. Ang and F. L. Liu, "A new energy decomposition method: Perfect in decomposition and consistent in aggregation," Energy, vol. 26, no. 6, pp. 537-548, 2001.

[12] B. W. Ang and F. Q. Zhang, "A survey of index decomposition analysis in energy and environmental studies," Energy, vol. 25, no. 12, pp. 1149-1176, 2000.

[13] Y. Wang, Y. Y. Cai, and H. Zhang, "The analysis on the factors of $\mathrm{CO}_{2}$ emission in households sector in China," Advanced Materials Research, vol. 518-523, pp. 5221-5231, 2012.

[14] G. R. Timilsina and A. Shrestha, "Factors affecting transport sector $\mathrm{CO}_{2}$ emissions growth in Latin American and Caribbean countries: an LMDI decomposition analysis," International Journal of Energy Research, vol. 33, no. 4, pp. 396-414, 2009.

[15] T. O. Mahony, "Decomposition of Ireland's carbon emissions from 1990 to 2010: an extended Kaya identity," Energy Policy, vol. 59, no. 4-5, pp. 573-581, 2013.

[16] M. R. Alves and V. Moutinho, "Decomposition analysis and Innovative Accounting Approach for energy-related $\mathrm{CO}_{2}$ (carbon dioxide) emissions intensity over 1996-2009 in Portugal," Energy, vol. 57, no. 3, pp. 775-787, 2013.

[17] F. Vinuya, F. DiFurio, and E. Sandoval, "A decomposition analysis of $\mathrm{CO}_{2}$ emissions in the United States," Applied Economics Letters, vol. 17, no. 10, pp. 925-931, 2010.

[18] P. F. González, M. Landajo, and M. J. Presno, “Tracking European Union $\mathrm{CO}_{2}$ emissions through LMDI (logarithmicmean Divisia index) decomposition. The activity revaluation approach," Energy, vol. 73, no. 7, pp. 741-750, 2014.

[19] J. M. Cansino, A. Sanchez-Braza, and M. L. Rodriguez-Arevalo, "Driving forces of spains $\mathrm{CO}_{2}$ emissions: a lmdi decomposition approach," Renewable \& Sustainable Energy Reviews, vol. 48, pp. 749-759, 2015.

[20] S. Jung, K. J. An, G. Dodbiba, and T. Fujita, "Regional energyrelated carbon emission characteristics and potential mitigation in eco-industrial parks in South Korea: logarithmic mean Divisia index analysis based on the Kaya identity, Energy, vol. 46, no. 1, pp. 231-241, 2012.

[21] W. Li, Y.-B. Shen, and H.-X. Zhang, "A factor decomposition on China's carbon emission from 1997 to 2012 Based on IPATLMDI model," Mathematical Problems in Engineering, vol. 2015, Article ID 943758, 14 pages, 2015.

[22] C. Ma and D. I. Stern, "Biomass and China's carbon emissions: A missing piece of carbon decomposition," Energy Policy, vol. 36, no. 7, pp. 2517-2526, 2008.

[23] X. Deng, Y. Yu, and Y. Liu, "Effect of construction land expansion on energy-related carbon emissions: empirical analysis of China and its provinces from 2001 to 2011," Energies, vol. 8, no. 6, pp. 5516-5537, 2015.

[24] W. Li and Q.-X. Ou, "Decomposition of China's carbon emissions intensity from 1995 to 2010: an extended Kaya identity," Mathematical Problems in Engineering, vol. 2013, Article ID 973074, 7 pages, 2013.

[25] G. Wang, X. Chen, Z. Zhang, and C. Niu, "Influencing factors of energy-related $\mathrm{CO}_{2}$ emissions in China: A decomposition analysis," Sustainability, vol. 7, no. 10, pp. 14408-14426, 2015.
[26] M. Zhang, S. Dai, and Y. Song, "Decomposition analysis of energy-related $\mathrm{co} 2$ emissions in south africa," Journal of Energy in Southern Africa, vol. 26, no. 1, pp. 67-73, 2015.

[27] Q. W. Wang, Y. H. Chiu, and C. R. Chiu, "Driving factors behind carbon dioxide emissions in China: a modified productiontheoretical decomposition analysis," Energy Economics, vol. 51, pp. 252-260, 2015.

[28] W. Zhang, K. Li, D. Q. Zhou, W. R. Zhang, and H. Gao, "Decomposition of intensity of energy-related $\mathrm{CO}_{2}$ emission in Chinese provinces using the LMDI method," Energy Policy, vol. 92, pp. 369-381, 2016.

[29] H. Zhou and Q. Zhang, "Factorizing changes in chinese carbon emission over 1994-2007 a LMDI decomposition analysis," China Energy Scientist Forum, pp. 277-281, 2010.

[30] Y. J. Zhang and Y. B. Da, “The decomposition of energy-related carbon emission and its decoupling with economic growth in China," Renewable \& Sustainable Energy Reviews, vol. 41, pp. 1255-1266, 2015.

[31] J. Song, Q. Song, D. Zhang, Y. Lu, and L. Luan, "Study on influencing factors of carbon emissions from energy consumption of Shandong province of China from 1995 to 2012," The Scientific World Journal, vol. 2014, Article ID 684796, 12 pages, 2014.

[32] C. Wang, F. Wang, H. Du, and X. Zhang, "Decomposing the influencing factors of energy-related carbon emissions over 1995-2011 in shandong province using the LMDI method," in Proceedings of the International Conference on Frontiers of Environment, Energy and Bioscience, October 2013.

[33] M. Song, X. Guo, K. Wu, and G. Wang, "Driving effect analysis of energy-consumption carbon emissions in the Yangtze River Delta region," Journal of Cleaner Production, vol. 103, pp. 620628, 2015.

[34] Z. Y. Gao, T. T. Li, X. Wang, and J. C. Peng, "Carbon emission factor decomposition model and empirical research of inner mongolia based on LMDI," Applied Mechanics \& Materials, vol. 291-294, pp. 1375-1379, 2013.

[35] Z. J. Huang, X. Ding, H. Sun, and S. Y. Liu, "Analysis of influencing factors of $\mathrm{CO}_{2}$ emissions from integrated steelworks based on LCA," Materials Science Forum, vol. 650, no. 6, pp. 9$16,2010$.

[36] J. Y. Zhang, Y. Zhang, Z. F. Yang, and S. S. Li, "Estimation of energy-related carbon emissions in beijing and factor decomposition analysis," Ecological Modelling, vol. 13, no. 252, pp. 16021608, 2013.

[37] Y. Chen and S. Lin, "Study on factors affecting energy-related per capita carbon dioxide emission by multi-sectoral of cities: a case study of Tianjin," Natural Hazards, vol. 77, no. 2, pp. 833846, 2015.

[38] P. Tapio, "Towards a theory of decoupling: degrees of decoupling in the EU and the case of road traffic in Finland between 1970 and 2001," Transport Policy, vol. 12, no. 2, pp. 137-151, 2005.

[39] L. C. D. Freitas and S. Kaneko, "Decomposing the decoupling of $\mathrm{CO}_{2}$ emissions and economic growth in Brazil," Ecological Economics, vol. 70, no. 8, pp. 1459-1469, 2011.

[40] W. W. Wang, R. Liu, M. Zhang, and H. N. Li, "Decomposing the decoupling of energy-related $\mathrm{CO}_{2}$ emissions and economic growth in Jiangsu Province," Energy for Sustainable Development, vol. 17, no. 1, pp. 62-71, 2013.

[41] J. Vehmas, J. Luukkanen, and J. Kaivo-oja, "Linking analyses and environmental Kuznets curves for aggregated material flows in the EU," Journal of Cleaner Production, vol. 15, no. 17, pp. 1662$1673,2007$. 
[42] Y. Kaya, "Impact of carbon dioxide emission control on GNP growth: interpretation of proposed scenarios," in Proceedings of the IPCC Energy and Industry Subgroup, Response Strategies Working Group, Paris, France, 1990.

[43] B. W. Ang, "The LMDI approach to decomposition analysis: a practical guide," Energy Policy, vol. 33, no. 7, pp. 867-871, 2005.

[44] L. B. Wu, S. Kaneko, and S. Matsuoka, "Driving forces behind the stagnancy of China's energy-related $\mathrm{CO}_{2}$ emissions from 1996 to 1999: the relative importance of structural change, intensity change and scale change," Energy Policy, vol. 33, no. 3, pp. 319-335, 2005.

[45] Beijing Bureau of Statistics, Beijing statistical Yearbook (2015), China Statistics Press, Beijing, China, 2015.

[46] Tianjin Bureau of Statistics, Tianjin statistical Yearbook (2015), China Statistics Press, Beijing, China, 2015.

[47] Hebei Provincial Bureau of Statistics, Hebei Economic Yearbook (2015), China Statistics Press, Beijing: China, 2015.

[48] NBS (National Bureau of Statistics of the People's Republic of China), China energy statistical yearbook (2001-2014), Statistics Press, Beijing, China, 2014.

[49] R. P. Song and S. Yang, GHG Protocol Tool for Energy Consumption in China (2.0), World Resources Institute, 2011.

[50] IPCC, 2006 IPCC Guidelines for National Greenhouse Gas Inventories [EB/OL], 2010 http://www.ipcc-nggip.iges.or.jp/ public/2006gl/index.html.

[51] F. Y. Fan and Y. L. Lei, "Factor analysis of energy-related carbon emissions: a case study of Beijing," Journal of Cleaner Production, 2015. 


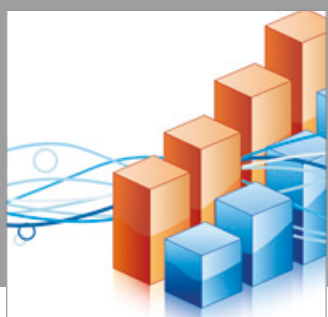

Advances in

Operations Research

vatersals

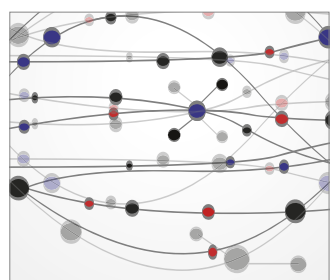

\section{The Scientific} World Journal
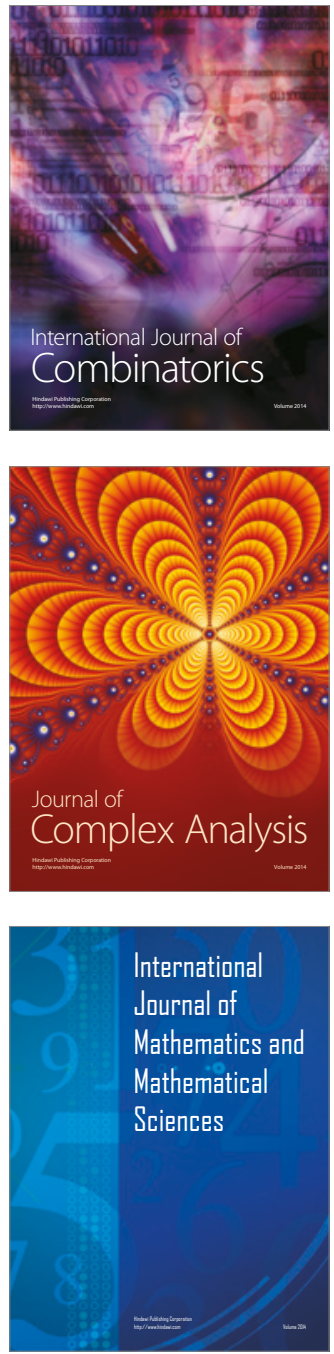
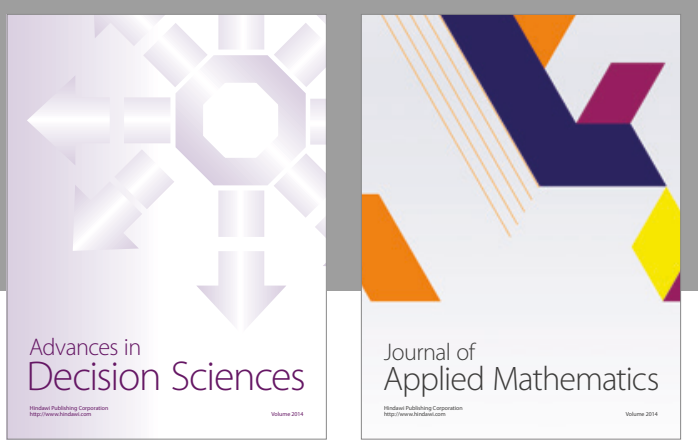

Algebra

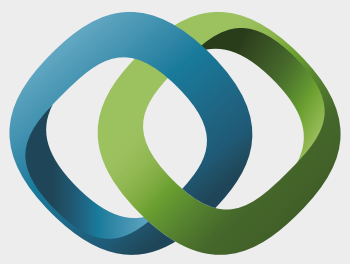

\section{Hindawi}

Submit your manuscripts at

https://www.hindawi.com
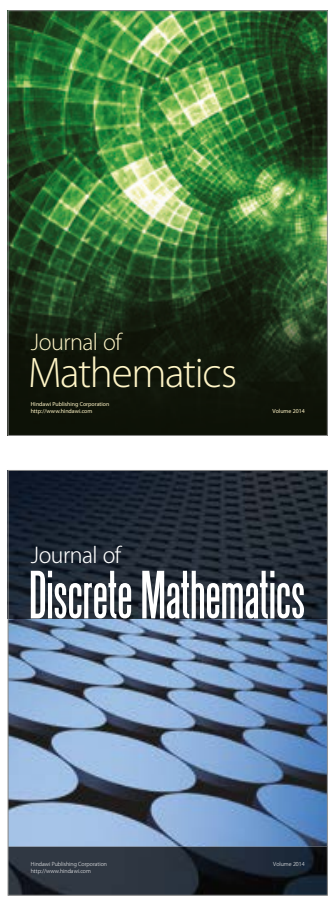

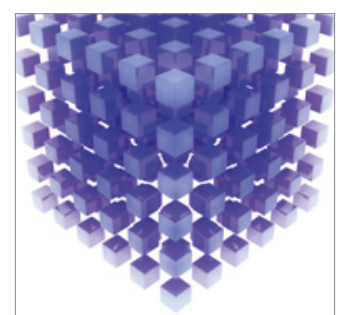

Mathematical Problems in Engineering
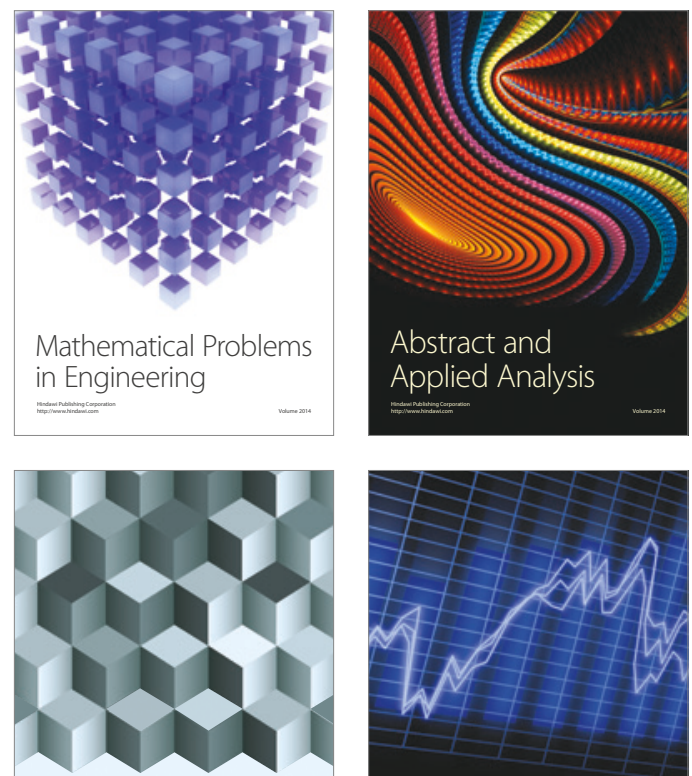

Journal of

Function Spaces

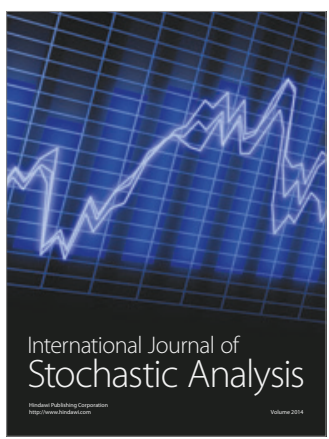

Probability and Statistics
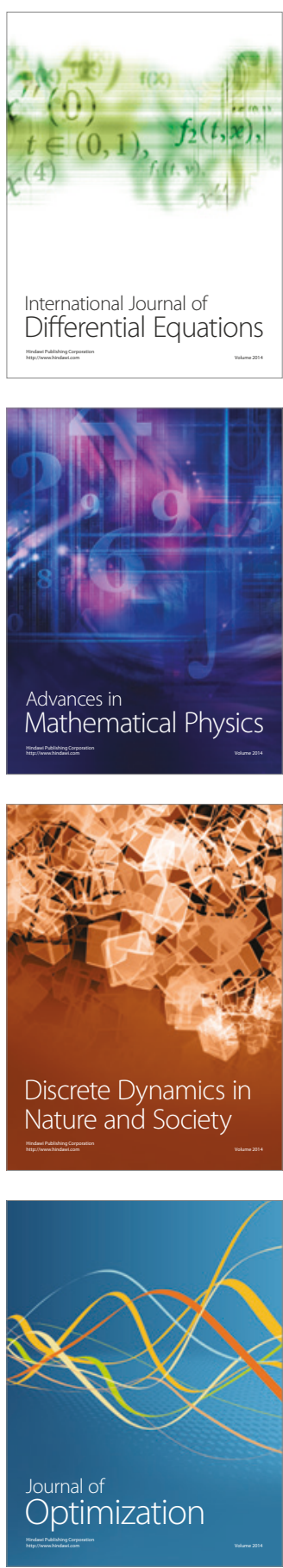